\title{
gSG6-P1 salivary biomarker discriminates micro-geographical heterogeneity of human exposure to Anopheles bites in low and seasonal malaria areas
}

André Barembaye Sagna ${ }^{1,2^{*}}$, Jean Biram Sarr ${ }^{1,3}$, Lobna Gaayeb ${ }^{1,4}$, Papa Makhtar Drame ${ }^{3}$, Mamadou Ousmane Ndiath", Simon Senghor ${ }^{1}$, Cheikh Saya Sow ${ }^{1}$, Anne Poinsignon ${ }^{3}$, Modou Seck', Emmanuel Hermann ${ }^{4}$, Anne-Marie Schacht ${ }^{1,4}$, Ngor Faye ${ }^{2}$, Cheikh Sokhna ${ }^{5}$, Franck Remoue ${ }^{6}$ and Gilles Riveau ${ }^{1,4}$

\begin{abstract}
Background: Over the past decade, a sharp decline of malaria burden has been observed in several countries. Consequently, the conventional entomological methods have become insufficiently sensitive and probably underestimate micro-geographical heterogeneity of exposure and subsequent risk of malaria transmission. In this study, we investigated whether the human antibody (Ab) response to Anopheles salivary gSG6-P1 peptide, known as a biomarker of Anopheles exposure, could be a sensitive and reliable tool for discriminating human exposure to Anopheles bites in area of low and seasonal malaria transmission.
\end{abstract}

Methods: A multi-disciplinary survey was performed in Northern Senegal where An. gambiae s.l. is the main malaria vector. Human IgG Ab response to gSG6-P1 salivary peptide was compared according to the season and villages in children from five villages in the middle Senegal River valley, known as a low malaria transmission area.

Results: IgG levels to gSG6-P1 varied considerably according to the villages, discriminating the heterogeneity of Anopheles exposure between villages. Significant increase of IgG levels to gSG6-P1 was observed during the peak of exposure to Anopheles bites, and decreased immediately after the end of the exposure season. In addition, differences in the season-dependent specific lgG levels between villages were observed after the implementation of Long-Lasting Insecticidal Nets by The National Malaria Control Program in this area.

Conclusion: The gSG6-P1 salivary peptide seems to be a reliable tool to discriminate the micro-geographical heterogeneity of human exposure to Anopheles bites in areas of very low and seasonal malaria transmission. A biomarker such as this could also be used to monitor and evaluate the possible heterogeneous effectiveness of operational vector control programs in low-exposure areas.

Keywords: Malaria, Salivary peptide, Biomarker, Low transmission, Anopheles exposure, Antibodies

\footnotetext{
* Correspondence: andre.sagna@espoir-sante.org

${ }^{1}$ Centre de Recherche Biomédicale (CRB) Espoir Pour La Santé, 269 Route de

la corniche, Sor - BP: 226, Saint-Louis, Sénégal

¿2aboratoire de parasitologie générale, Département de Biologie Animale,

Université Cheikh Anta Diop, Dakar, Sénégal

Full list of author information is available at the end of the article
} 


\section{Background}

Improvement of diagnosis, treatment and preventive methods have brought about a sharp decrease of malaria transmission in several regions, particularly in Sub-Saharan Africa [1]. Over the past decade, several countries which formerly had a high malaria burden have seen over $50 \%$ reduction in malaria burden [2]. Consequently, the current methods for monitoring malaria have become increasingly difficult. Indeed, the evaluation of Anopheles population density is the first step to define the risk of transmission (Entomological Inoculation Rate, EIR) $[3,4]$. EIR estimates the number of infective bites a person receives per unit of time and thus the risk of exposure to malaria. However, the intensity of exposure to Anopheles bites, and thus the risk of malaria transmission, may be different from a local setting to another within a single micro-geographical region [5-7] and even between neighbouring villages or houses [8]. This heterogeneity of exposure to Anopheles is particularly important in areas of low malaria transmission, where only few infected mosquitoes are sampled and where focal hotspots of malaria transmission may exist [9]. These residual transmission foci may hamper elimination efforts by sending transmission to the wider community $[10,11]$. Moreover, the evaluation of the real exposure to Anopheles, and thus the risk of malaria transmission by the EIR, seems irrelevant and not adapted in these contexts because the number of collected mosquitoes are often below the detection limits of commonly used trapping methods [7,9]. It has been shown there is significant malaria transmission in the Senegal River Basin, yet entomological data showed a very low exposure to Anopheles bites [12,13]. People living in such settings could be at a high risk of malaria morbidity and mortality because of the absence of protective immunity due to low levels of parasite exposure. The development of simple, rapid and sensitive tools is therefore needed to identify the micro-geographical variations of exposure and thus the risk of transmission in areas of low or very low exposure to Anopheles. Those tools could be useful for targeting areas where the control should be strengthened.

Several studies have shown a relationship between human antibody $(\mathrm{Ab})$ responses to whole arthropod saliva and the human exposure to triatomines [14,15], tsetse flies [16,17], sandflies [18-20], Aedes and Culex [21,22], and Anopheles species [23-25]. However, many areas exhibit several species of blood-sucking arthropods $[26,27]$, therefore high specificity and sensitivity were needed to evaluate a specific arthropod exposure by salivary-based immunoassays. Indeed, many cross-reactions have been reported for whole saliva between different vectors and also between closely related species [28]. During the past 10 years, advances in the study of transcriptome and proteome of Anopheles gambiae (An. gambiae) identified gSG6, a small salivary protein specific to Anopheles species [29] and presenting antigenic properties. The whole gSG6 protein was detected by IgG Ab from children exposed to An. gambiae bites and was then proposed as a biomarker of exposure [30,31]. In order to optimize the gSG6 biomarker, Poinsignon et al., by coupling bioinformatic and immuno-epidemiological approaches, identified one peptide of gSG6, the gSG6-P1 peptide, as a relevant and specific biomarker of Anopheles exposure [30]. The IgG response to this specific peptide is perfectly correlated to both human exposure to bites of An. gambiae and An. funestus [32]. In addition, it has been suggested that this biomarker was particularly suited to assess low-level exposure to An. gambiae bites [33]. Nevertheless, this biomarker has not been validated for discriminating micro-geographical variation of exposure in a low and seasonal malaria transmission area.

The present study aims to assess if the gSG6-P1 salivary peptide could be a sensitive tool for discriminating human exposure to An. gambiae bites in a micro-geographical context of low and seasonal malaria transmission. To this end, the specific IgG response to gSG6-P1 was evaluated during 1.5 years follow-up (rainy and dry seasons) in children living in five different villages in the middle Senegal River valley.

\section{Methods}

\section{Study area and population}

This study was carried out in Northern Senegal (Podor District) along the Senegal River Basin (Figure 1). The studied majority of the population belongs to the Peulh ethnic group. This region is a dry savannah, with a dry season from November to June and a short rainy season from July to October (annual rainfall $<400 \mathrm{~mm}$ in 2009) [34]. In this region, malaria transmission is very low, seasonal and mainly due to An. gambiae s.l. [35].

A longitudinal survey was performed in five villages (Agniam, Niandane, Ndiayene Pendao, Guede and Fanaye) and five visits (October 2008, January, June, October 2009 and January 2010) were carried out. The study cohort consisted of 410 children aged from 1 to 9 years, but only the children present and blood sampled at each of the 5 visits were included for the immunological analysis $(n=265)$. Age mean at the beginning of the study differed between these five villages: Agniam (mean \pm SD): $4.40 \pm$ 2.48, Niandane: $5.17 \pm 2.42$, Pendao: $4.49 \pm 2.61$, Guede: $5.84 \pm 3.06$ and Fanaye: $5.32 \pm 2.46)(\mathrm{p}=0.008)$. Thick blood smears were stained with Giemsa to identify Plasmodium species and the number of malaria parasites was counted. Parasite density was defined as the number of Plasmodium parasites/ $\mu$ l of blood. In parallel, sera collected by finger prick were used for immunological tests. In June 2009, a large scale distribution of LongLasting Insecticidal Nets (LLINs) was performed around 


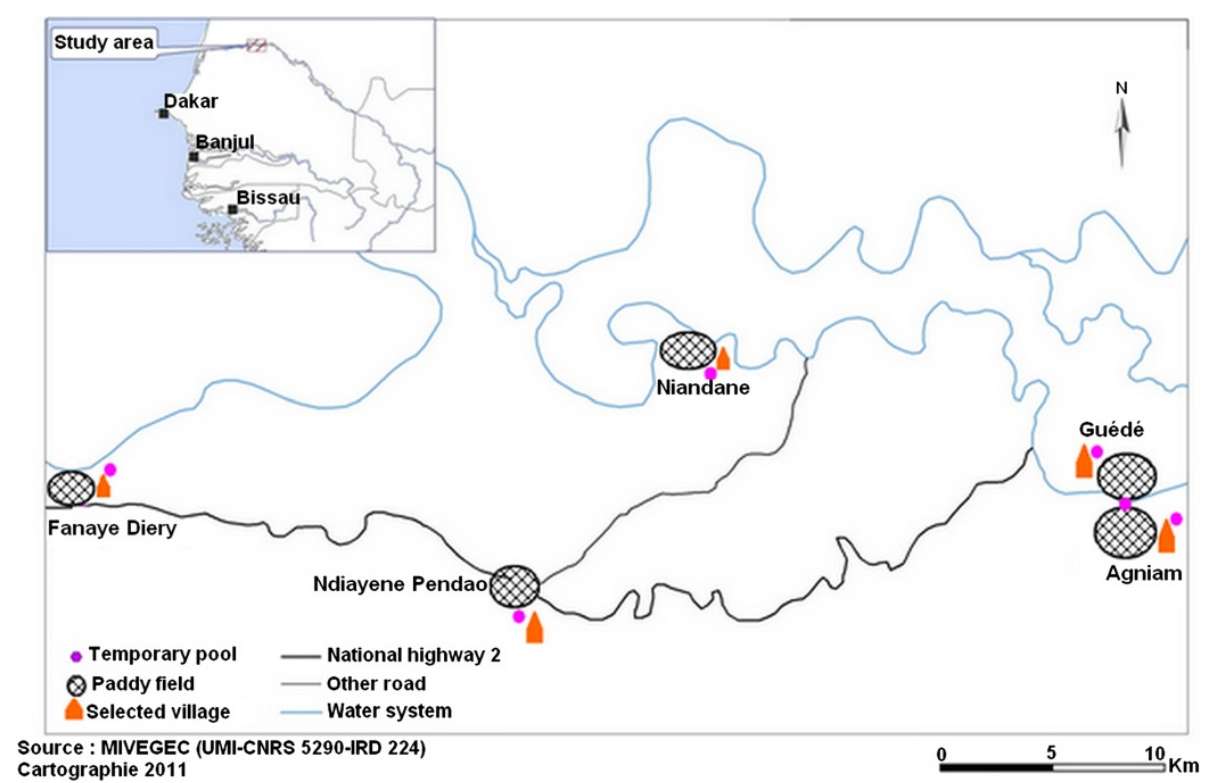

Figure 1 Localization of studied villages.

the endemic regions, and particularly in the studied region by the National Malaria Control Program (NMCP) of Senegal [36].

The present study was approved by the National Ethics Committee of the Ministry of Health of Senegal, (October 2008; 0084/MSP/DS/CNRS, ClinicalTrials.gov ID: NCT01545115). Oral and written informed consents were obtained from the parents or the legal guardians of the children.

\section{Mosquito sampling and entomological analysis}

Mosquito collection procedures and their treatment in the laboratory were previously described by Ndiath et al. [35]. Briefly, Human Landing Catches (HLC) were performed from 07:00 p.m to 07:00 a.m for two non consecutive nights. Four adult volunteer collectors were positioned at two different sites in each village (2 collected mosquitoes indoor and 2 outdoor). Pyrethrum Spray Catches (PSC) were conducted in five randomly selected rooms for one day among those not having used any form of insecticide or repellent during the previous week and being different from those used for HLC. Deltamethrin $\left(\right.$ Yotox $^{\circledR}$ ) was sprayed inside the closed rooms for 30-45 seconds. After 10 minutes, dead or immobilized mosquitoes were collected. Anopheles species were identified using morphological characteristics according to identification rules [37]. Human Biting Rate (HBR) was estimated by the number of $A n$. gambiae bites/human/night (BHN) sampled by HLC. It was calculated by dividing the number of An. gambiae caught by the total person-night for the period. The density of $A n$. gambiae females resting in a room was estimated by the number of An. gambiae
Females per Room per Night (FRN) sampled by PSC. It was calculated by dividing the number of An. gambiae species identified by the total randomized-rooms for the period, as previously described [35].

\section{Salivary peptide gSG6-P1}

The gSG6-P1 peptide was designed as previously described [30]. It was synthesized and purified $(>95 \%)$ by Genepep SA (St-Clément de Rivière, France). Peptide was shipped in lyophilized form and then suspended in $0.22 \mu \mathrm{m}$ ultra-filtered water and frozen at $-80^{\circ} \mathrm{C}$ until use.

\section{Evaluation of human IgG antibody levels (ELISA)}

ELISAs were carried out on sera to quantify IgGs to the gSG6-P1 peptide as previously described [38]. Briefly, the gSG6-P1 antigen $(20 \mu \mathrm{g} / \mathrm{mL})$ was coated onto Maxisorp plates (Nunc, Roskilde, Danemark) using 100 $\mu \mathrm{L} /$ well for $2 \mathrm{~h} 30 \mathrm{~min}$ at $37^{\circ} \mathrm{C}$. Plate wells were then blocked for $1 \mathrm{~h}$ at room temperature with $300 \mu \mathrm{L}$ of protein-free blocking buffer, $\mathrm{pH}$ 7.4 (Thermoscientific, Rockford, USA). Individual sera were incubated in duplicate at $4^{\circ} \mathrm{C}$ overnight at a $1 / 20$ dilution (in PBS with $1 \%$ Tween). This dilution was determined as optimal after several preliminary experiments. Plates were then incubated for $90 \mathrm{~min}$ at $37^{\circ} \mathrm{C}$ with $100 \mu \mathrm{L}$ of mouse biotinylated $\mathrm{Ab}$ against human IgG (BD Pharmingen, San Diego CA, USA) diluted $1 / 2000$ in PBS with $1 \%$ Tween. Plate wells were then washed and incubated for $1 \mathrm{~h}$ at $37^{\circ} \mathrm{C}$ with $100 \mu \mathrm{L}$ of peroxidase-conjugated streptavidin (Amersham, les Ulis, France). Colorimetric development was carried out using ABTS (2.2'-azino-bis (3 ethylbenzthiazoline 6-sulfonic acid) diammonium; 
Sigma, St Louis, MO, USA) in $50 \mathrm{mM}$ citrate buffer (Sigma, $\mathrm{pH}=4$, containing $0.003 \% \mathrm{H} 2 \mathrm{O} 2$ ) and absorbance (OD) was measured at $405 \mathrm{~nm}$.

Individual results were expressed as the $\triangle \mathrm{OD}$ value: $\triangle \mathrm{OD}=\mathrm{ODxODn}$, where ODx represents the mean of individual optical density (OD) value in both wells with gSG6-P1 antigen and ODn the individual OD value for each serum without gSG6-P1 antigen. Anti-gSG6-P1 IgG levels were also assayed in non-Anopheles exposed individuals ( $\mathrm{n}=12$ - neg; North of France) in order to quantify the non-specific background Ab level and to calculate the specific immune response threshold (TR): $\mathrm{TR}=$ mean $\left(\Delta \mathrm{OD}_{\text {neg }}\right)+3 \mathrm{SD}=0.180$. An exposed individual was then classified as an immune responder (IR) if its $\Delta \mathrm{OD}>0.180$.

\section{Statistical analysis of data}

Data were analysed with Graph Pad Prism ${ }^{\circledR}$ (Graph Pad Software, San Diego, USA). After checking that values in each group did not fit a Gaussian distribution, one-way analysis of variance (ANOVA) was used to compare age differences between children of all villages. The nonparametric Mann-Whitney U test was used to compare $\mathrm{Ab}$ response levels between two villages while the Kruskal-Wallis test was used for the comparison of $\mathrm{Ab}$ response levels between more than two villages. The Wilcoxon matcher-paired test was used for the comparison of $\mathrm{Ab}$ response levels between two visits in each village. All differences were considered as significant at $\mathrm{p}<0.05$.

\section{Results}

\section{Entomological and parasitological data}

Previous results indicated that malaria transmission in the study villages was low and seasonal with an EIR (number of infective bites/person/night) ranging from 0 to 0.059 [35]. The prevalence of $P$. falciparum infection was also low to moderate (ranging from 0 to $31.7 \%$ ), season-dependent and peaked in January 2009, after the peak of Anopheles exposure (Table 1). However, malaria prevalence in October 2009 was very low compared to October 2008 in all studied villages. Such a decrease may be related to the implementation of LLINs during the end of the dry season (June 2009) by NMCP in the studied area. In studied villages, the large majority $(80 \%)$ of anopheline species belong to the An. gambiae complex, as previously reported [35]. Anopheles density (BHN and FRN) was generally low and variable according to the village (Table 1). Whatever the considered entomological parameters (BHN or FRN), the higher density was generally observed in Agniam, Niandane and Pendao villages compared to Guede and Fanaye villages. The FRM results indicated however, that Agniam could be considered as the village presenting the highest exposure risk to $A n$. gambiae exposure, compared to other villages. A marked increase in Anopheles density was observed during both rainy seasons (October 2008 and October 2009) compared to the dry season (January through June 2009) in all studied villages except Pendao in October 2009.

\section{IgG response levels to gSG6-P1 according to age group} Specific IgG responses to An. gambiae s.l. gSG6-P1 peptide were analyzed in October 2008 (period of higher exposure to Anopheles) in children aged 1 to 9 years according to age groups (1-2, 3-4, 5-6, 7-8 and 9 years old). Cumulative immunological data from all villages indicated that only $44 \%$ of children were immune responders. The median of IgG response to gSG6-P1 differed significantly according to age groups $(\mathrm{p}=0.039)$. Specific IgG level was low in children from the 1-2 years age group, increased in the 3-4 years age group, and then remained high from this age to 9 years old (data not shown).

\section{IgG response levels to gSG6-P1 according to the village}

Anti-gSG6-P1 IgG levels were compared in the five studied villages at the peak period of exposure to Anopheles bites (October 2008, Figure 2). Despite the inter-individual heterogeneity observed in each village, the median of specific IgG Ab levels in children varied significantly according to villages $(\mathrm{p}<0.0001)$. Children from Agniam (A) developed significantly higher IgG response levels to gSG6-P1 than those from other villages $(\mathrm{p}<0.0001 \mathrm{com}-$ pared to each village value). In contrast, no significant differences in specific IgG levels were found between children from villages of Niandane $(\mathrm{N})$, Pendao $(\mathrm{P})$ and Guede (G). IgG Ab levels to gSG6-P1 were significantly lower in children from Fanaye compared to the IgG levels of those from other villages (every $\mathrm{p}<0.0001)$. These differences of anti-gSG6-P1 IgG levels according to the studied villages were also observed whatever the considered age-group (1-5 or 6-9 years old age groups, data not shown). In the same way, the percentage of immune responders was high in Agniam (80.49\%), moderate in Niandane (54.93\%), Pendao (37.84\%) and Guede (39.02\%) and very low in Fanaye $(9.33 \%)$ (Table 1). Taken together, these results indicated that the specific IgG levels and the percentage of immune responders to gSG6-P1 peptide were villagedependent.

However, some inconsistencies were observed between immunological and entomological results in some villages and seasons accordingly. Indeed, a low percentage of immune responders could be observed in villages and/or seasons where high HBR were detected and vice versa (Table 1). For instance, in Fanaye, the percentage of immune responders was nil while entomological data showed a rate of $3.87 \mathrm{BHN}$, in October 2009. Likewise, in October 2009 in Guede, BHN was 9.37 and the percentage of immune responders was $43.9 \%$, while similar levels of biting rates of $8.37 \mathrm{BHN}$ in October 2008 in Agniam showed a higher rate of immune response at $80 \%$. 
Table 1 Characteristics of the studied population: entomological, parasitological and immunological data

\begin{tabular}{|c|c|c|c|c|c|c|}
\hline \multirow[t]{2}{*}{ Villages } & \multirow[t]{2}{*}{ Variables } & \multicolumn{5}{|c|}{ Periods of survey } \\
\hline & & October 2008 & January 2009 & June 2009 & October 2009 & January 2010 \\
\hline \multirow[t]{4}{*}{ Agniam ( $n=41)$} & An. gambiae Bites/human/night & 8.37 & 0 & 1.62 & 12.5 & 0.5 \\
\hline & An. gambiae Females/Room/night & 41 & 0.2 & 7.6 & 28.4 & 4.4 \\
\hline & $\%$ P. falciparum prevalence $(95 \% \mathrm{Cl})$ a & $12.20(2.18 ; 22.22)$ & $19.50(7.38 ; 31.64)$ & $4.90(-1.77 ; 11.47)$ & 0.00 & $2.40(-2.28 ; 7.16)$ \\
\hline & $\%$ of immune responders $(95 \% \mathrm{Cl}) \mathrm{b}$ & $80.49(68.36 ; 92.62)$ & $34.15(19.63 ; 48.67)$ & $29.27(15.34 ; 43.2)$ & $82.92(71.41 ; 94.45)$ & $24.40(11.25 ; 37.53)$ \\
\hline \multirow[t]{4}{*}{ Niandane $(n=71)$} & An. gambiae Bites/human/night & 13.87 & 0.62 & 1.5 & 11.12 & 0 \\
\hline & An. gambiae Females/Room/night & 11.6 & 0.6 & 1.4 & 9.4 & 0 \\
\hline & $\%$ P. falciparum prevalence $(95 \%$ Cl) & $21.10(11.63 ; 30.63)$ & $24.00(14.01 ; 33.87)$ & $4.20(-0.45 ; 8.91)$ & $4.20(-0.45 ; 8.91)$ & 0.00 \\
\hline & $\%$ of immune responders ( $95 \% \mathrm{Cl}$ ) & $54.93(43.36 ; 66.5)$ & $21.12(11.63 ; 30.63)$ & $18.30(9.30 ; 27.30)$ & $33.80(22.8 ; 44.8)$ & $14.08(5.99 ; 22.17)$ \\
\hline \multirow[t]{4}{*}{ Pendao $(n=37)$} & An. gambiae Bites/human/night & 9.25 & 0.87 & 3.5 & 0.87 & 0.62 \\
\hline & An. gambiae Females/Room/night & 20.4 & 0.6 & 7.6 & 4.8 & 0.2 \\
\hline & $\%$ P. falciparum prevalence $(95 \% \mathrm{Cl})$ & $5.40(-1.88 ; 12.7)$ & $16.20(4.34 ; 28.1)$ & $2.70(-2.52 ; 7.92)$ & 0.00 & 0.00 \\
\hline & $\%$ of immune responders $(95 \% \mathrm{Cl})$ & $37.84(22.21 ; 53.47)$ & $24.32(10.5 ; 38.14)$ & $10.81(0.8 ; 20.82)$ & $32.43(17.37 ; 47.51)$ & $8.11(-0.69 ; 16.91)$ \\
\hline \multirow[t]{4}{*}{ Guede $(n=41)$} & An. gambiae Bites/human/night & 7.12 & 0 & 0.25 & 9.37 & 1.75 \\
\hline & An. gambiae Females/Room/night & 9.8 & 0 & 3 & 7.8 & 3.6 \\
\hline & $\%$ P. falciparum prevalence $(95 \% \mathrm{Cl})$ & $9.75(0.68 ; 18.84)$ & $31.70(17.47 ; 45.95)$ & $7.30(-0.65 ; 15.29)$ & 0.00 & $4.90(-1.71 ; 11.47)$ \\
\hline & $\%$ of immune responders ( $95 \% \mathrm{Cl}$ ) & $39.02(24.09 ; 53.95)$ & $7.32(-0.65 ; 15.29)$ & $21.95(9.28 ; 34.62)$ & $43.90(28.71 ; 59.09)$ & $12.19(2.18 ; 22.22)$ \\
\hline \multirow[t]{4}{*}{ Fanaye $(\mathrm{n}=75)$} & An. gambiae Bites/human/night & 2.75 & 0 & 0.75 & 3.87 & 0.37 \\
\hline & An. gambiae Females/Room/night & 7.8 & 1.4 & 1.2 & 7.4 & 1.2 \\
\hline & $\%$ P. falciparum prevalence $(95 \%$ Cl) & $16.00(8.76 ; 25.9)$ & $18.70(9.85 ; 27.49)$ & $2.70(-0.98 ; 6.32)$ & $1.30(-1.26 ; 3.92)$ & 0.00 \\
\hline & $\%$ of immune responders $(95 \% \mathrm{Cl}$ ) & $9.33(2.75 ; 15.91)$ & 0.00 & $1.33(-1.26 ; 3.92)$ & 0.00 & $1.33(-1.26 ; 3.92)$ \\
\hline
\end{tabular}

Bites/human/night= number of An. gambiae caught by Human Landing Catches;

Females/Room/Night= number of An. gambiae females caught by Pyrethrum Spray Catches;

a Lower and upper $95 \%$ confidence interval of Plasmodium falciparum prevalence.

b Lower and upper $95 \%$ confidence interval of Immune responders to gSG6-P1 salivary peptide. 


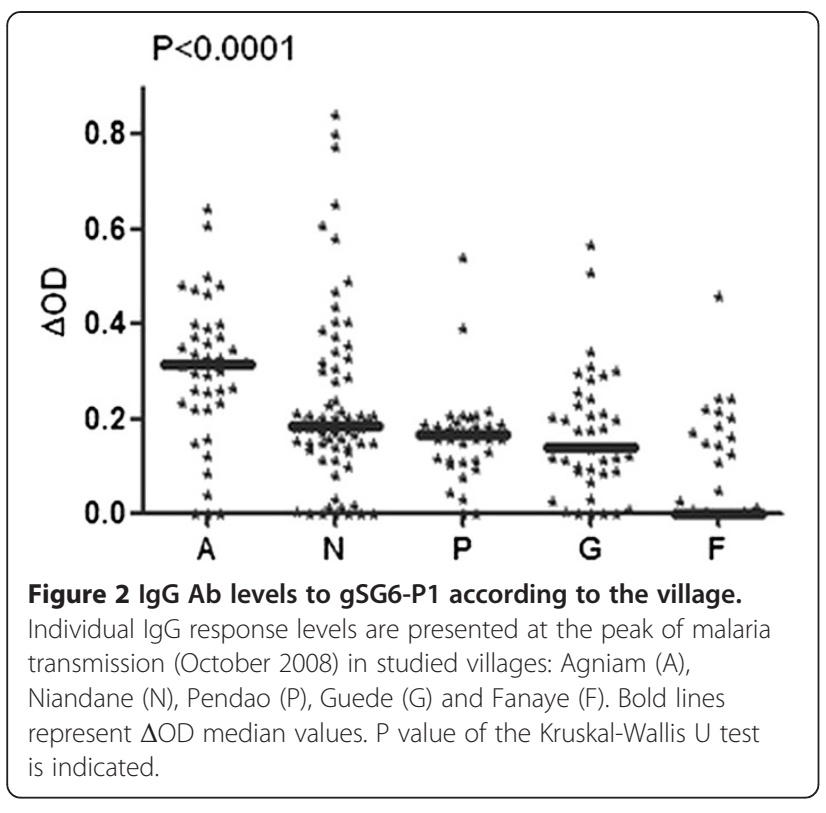

Seasonal variation of the IgG levels to gSG6-P1 peptide The IgG response levels to gSG6-P1 peptide were evaluated in each village during a 16 months follow-up (Figure 3). As a general pattern, the anti-gSG6-P1 IgG levels were significantly higher during the period of high exposure to Anopheles (October 2008; rainy season) compared to other periods. The IgG levels then decreased significantly at the beginning of the dry season (January 2009) $(\mathrm{p}<0.05$ in all villages, except Fanaye) and remained low until the end of this season. In October 2009 , this season-dependent variation of the IgG levels to gSG6-P1 was only observed in Agniam, Pendao and Guede but not in Niandane where specific IgG responses remained low compared to June 2009 (dry season) $(\mathrm{p}=0.147)$. In Fanaye, a very low IgG response level was observed regardless of the period studied. A similar seasonal-dependent variation was observed for the percentage of immune responders (Table 1) where the number of responders was higher during October 2008 than in June 2009.

Furthermore, specific IgG levels to gSG6-P1 in October 2009 were lower compared to those recorded in October 2008, only in children living in Agniam and Niandane villages $(\mathrm{p}<0.0016$ and $\mathrm{p}<0.0001$, respectively). Entomological data indicated similar densities of Anopheles between October 2008 and October 2009 in Agniam and in Niandane villages (Table 1). No significant differences in IgG levels between October 2008 and 2009 were observed in the three other villages.

\section{Discussion}

In the context of low malaria transmission, the current methods used to evaluate the intensity of transmission, such as EIR or Plasmodium parasitemia, present substantial limitations. Alternative methods to estimate Anopheles density and human exposure would be of great value, allowing epidemiological studies when the use of classical methods may not be relevant such as in low transmission settings. In this respect, our present study investigated whether the gSG6-P1 salivary peptide could be a sensitive and reliable biomarker allowing the detection of micro-geographical heterogeneity of human exposure to Anopheles bites in particular settings.

Our results showed that the IgG Ab levels to gSG6-P1 peptide and the percentage of immune responders varied between the five studied villages. These results suggest that the immune response to gSG6-P1 salivary peptide could identify villages more at risk of malaria than others even in an area presenting low exposure to vectors. The high heterogeneity of exposure to Anopheles bites observed in the studied villages may be explained by the presence of different surrounding landscapes among them $[39,40]$ and/or the proximity of the river. Indeed, several studies have shown a positive correlation between malaria transmission and the distance to a river as a potential breeding site $[41,42]$. Nevertheless, this factor is not sufficient to explain the variation of Anopheles exposure between villages. In fact, Agniam, Guede and Niandane, three villages located near the river, presented different levels of IgG responses to gSG6-P1. A possible explanation of the high human-Anopheles contact in Agniam compared to Guede, for instance (villages only separated by the river) could be the influence of man-made conditions. In this area, Ndiath et al. have shown that Anopheles density variation was more related to the presence of ditch water used for gardening, rice cultivation, manufacture of bricks or animal watering, than the proximity of the river [35]. Thus, Anopheles exposure could be influenced by local human activity and/ or household factors which may favor the development of artificial breeding sites, allowing the emergence of adults [35]. Overall, these results confirm that the gSG6-P1 peptide could measure the real human-vector contact and is sensitive enough to detect small-scale variations of vector bites in areas with very low-exposure [32,33,43].

However, inconsistencies observed between immunological parameters and entomological results in some villages (e.g.: Agniam vs. Guede) and/or according to seasons suggest that other factors could be taken into account in measuring the heterogeneity of man-vector contact. The use of vector control tools (spray, ITNs or LLINs, personal protection...) as well as household characteristics (traditional, modern...) could significantly reduce the human-vector contact. Moreover, individual exposure to Anopheles was evaluated by HLC (using adult volunteers) and therefore, could present considerable limitations for evaluation of entomological 


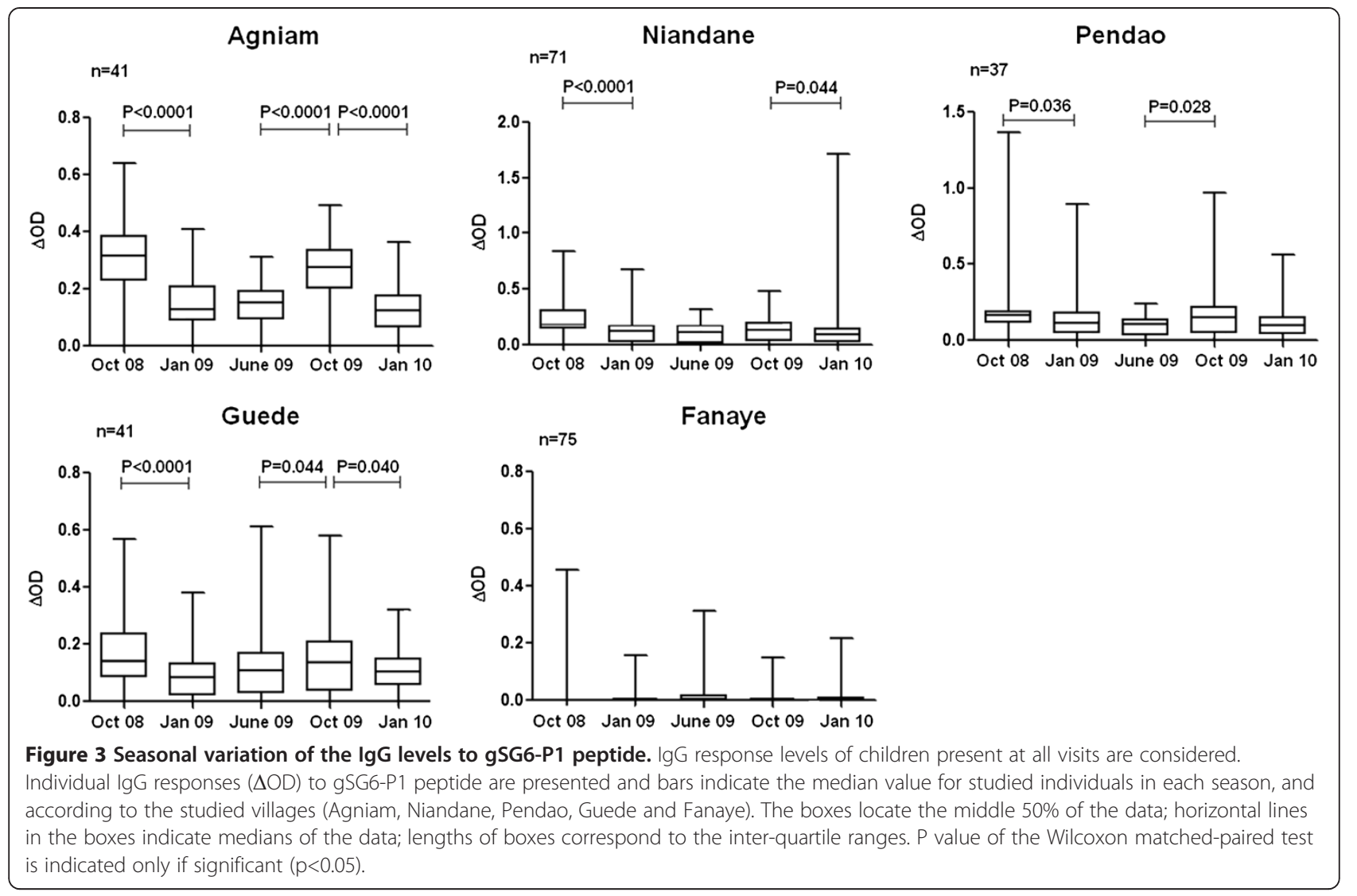

exposure in children $[44,45]$. Entomological data was also collected in limited number of areas (five randomised houses/village) and cannot represent the individual exposure to Anopheles bites and its micro-geographical variations. The use of the gSG6P1 biomarker could therefore be relevant and useful for assessing human exposure to Anopheles bites at the population and individual level.

We also reported that both IgG $\mathrm{Ab}$ levels and the percentage of immune responders to the salivary biomarker varied according to the season and remained high in October corresponding to the peak of exposure to Anopheles bites. This seasonal variation of specific IgG response was associated to the similar variations of entomological data, as has been reported in previous studies $[31,38,46]$. Moreover, the drop of IgG response observed in January 2009, only three months after the peak of exposure (October 2008), confirmed that the anti-gSG6-P1 IgG responses were short-lived, decreasing after a few months of no exposure [33,47]. These observations indicate that the $\mathrm{Ab}$ responses to gSG6-P1 antigen are transient and sensitive to the seasonal variations of human exposure to Anopheles bites. Similar seasonal fluctuations of Ab to gSG6-P1 were reported in some other epidemiological studies taking place elsewhere in Africa [33,47]. Indeed, a drop in the anti-saliva IgG response has been previously described in soldiers exposed to An. gambiae, three months after their return from a travel period in tropical Africa [48] and in children from Angola 6 weeks after the interruption of exposure by bednet use [47]. This concomitant variation of IgG response according to season and consequently to Anopheles exposure indicates that the gSG6-P1 biomarker could be used as an alternative tool when trapping methods are difficult to apply, are fastidious and not applicable at large scale $[49,50]$, particularly in low or very low endemic areas.

In addition, we observed village-dependent differences between 2009 and 2008. Indeed, specific IgG Ab levels to gSG6-P1 significantly increased only in Agniam, Pendao and Guede in October 2009 compared to June 2009, but not in Niandane village. Moreover, specific IgG responses were lower in October 2009 compared to October 2008 in Agniam and Niandane, whereas entomological data indicated that Anopheles populations remained similar at these two time periods. As gSG6-P1 biomarker has clearly been shown as a pertinent indicator for measuring the efficacy of LLINs [36], the present data could indicate a change in human-vector contact between both periods. Indeed, human-vector contact may be influenced by several human or environmental factors [51]. The large scale implementation of LLINs conducted by the NMCP in June 2009 [36] could explain the reduced probability of being bitten by Anopheles and 
partly explain the observed immunological results. However, it is necessary to indicate that despite this implementation of LLINs, some individuals presented gSG6-P1 specific IgG responses indicating that they were still exposed to Anopheles bites. Altogether, we can hypothesize that the observed differences between villages could be due to a different distribution, owners or real use of LLINs by children according to villages. For instance, it could be hypothesized that the efficacy of LLINs implementation and use by children could be higher in Niandane village, and also in Agniam to a lesser extent, compared to other villages. Some factors such as genetics, nutritional status, population displacement (holidays spent in an area of low/ high exposure for school-age children), micro-climatic and micro-habitat variations from the studied villages, could not be excluded to explain the observed differences. Nevertheless, these data suggest that the gSG6-P1 biomarker could represent an alternative tool for evaluating the effectiveness of vector control strategies by The National Malaria Control Programmes and variations of effectiveness between villages and environmental and epidemiological contexts [38,43]. Future studies evaluating the impact of LLINs on malaria transmission in children could be performed by a multi-disciplinary approach where immune response to salivary biomarker would be integrated.

\section{Conclusions}

The measurement of human Ab responses to gSG6-P1 represents a new tool for evaluating human exposure to Anopheles vector bites. This specific Ab response seems to be sensitive, reliable and complementary to classical entomological methods used for evaluating the heterogeneity of human exposure to Anopheles bites, in areas with low-levels of malaria transmission. This biomarker could be used as a pertinent tool to estimate short term variations of vector exposure and as a promising indicator to evaluate the effectiveness of vector control strategies particularly in areas with low endemicity. In addition, a biomarker such as this would allow targeting for anti-malaria control programmes in specific areas and in seasons where malaria risk is highest.

\section{Competing interests}

The authors declare that they have no competing interests.

\section{Authors' contributions}

ABS carried out the immunological assessments, statistical analysis and drafted the manuscript. LG and JBS helped to draft the manuscript. JBS, LG, MON, CB, SS, CSS, MS, contributed to field activities and microscopic examination. PMD, $A P, E H, A M S, N F, C S$ provided substantial improvement of the manuscript. FR, GR provided the scientific supervision, interpretation of the data, and revised the manuscript. All authors approved the final version of the manuscript.

\section{Acknowledgments}

The authors gratefully acknowledge the populations of Agniam, Niandane, Guede, Ndiayene Pendao and Fanaye villages, for their participation in this study. We also thank Soihibou Guindo and Samy Boutouaba-Combe (CRB-EPLS) for their technical assistance in the field and advice on statistical analysis, respectively

André Barembaye Sagna was supported by a fellowships provided by CRBEPLS and Jean Biram Sarr by a post-doctoral fellowship provided by the "Infectiopole Sud" Foundation (Marseille, France). Lobna Gaayeb received support from the Region Nord-Pas de Calais and the Pasteur Institute of Lille. This research was supported by the Biomedical Research Center Espoir Pour La Santé (EPLS) and the Research Institute for Development (IRD-Direction de la Valorisation au Sud) with a financial participation of the FSD "Fond Social de Développement", (BIOMARQPAL ref 2008-5901) Embassy of France in Senegal.

\section{Author details}

${ }^{1}$ Centre de Recherche Biomédicale (CRB) Espoir Pour La Santé, 269 Route de la corniche, Sor - BP: 226, Saint-Louis, Sénégal. 'Laboratoire de parasitologie générale, Département de Biologie Animale, Université Cheikh Anta Diop, Dakar, Sénégal. ${ }^{3}$ Institut de Recherche pour le Développement, UMR 224 MIVEGEC, 911 avenue Agropolis - B: 64501, Montpellier F-34394, France. ${ }^{4}$ Centre d'Infection et d'Immunité de Lille (CIIL), Inserm U1019, CNRS UMR 8204, Université Lille Nord de France, Institut Pasteur de Lille, 1 rue du Pr. Calmette, Lille cedex 59019, USA. Institut de Recherche pour le Développement (IRD), UMR 198 URMITE Campus international de Hann, IRD - BP : 1386, Dakar, CP 18524, Sénégal. Institut de Recherche pour le Développement (IRD), UMR 224 MIVEGEC - Centre de Recherche

Entomologique de Cotonou (CREC), Cotonou, Benin.

Received: 10 December 2012 Accepted: 8 March 2013

Published: 15 March 2013

\section{References}

1. WHO: World Malaria Report 2011. Geneva: World Health Organisation; 2011.

2. O'Meara WP, Mangeni JN, Steketee R, Greenwood B: Changes in the burden of malaria in sub-Saharan Africa. Lancet Infect Dis 2010, 10:545-555.

3. Drakeley C, Schellenberg D, Kihonda J, Sousa CA, Arez AP, Lopes D, Lines J, Mshinda H, Lengeler C, Armstrong Schellenberg J, Tanner M, Alonso P: An estimation of the entomological inoculation rate for Ifakara: a semiurban area in a region of intense malaria transmission in Tanzania. Trop Med Int Health 2003, 8:767-774.

4. Hay SI, Rogers DJ, Toomer JF, Snow RW: Annual Plasmodium falciparum entomological inoculation rates (EIR) across Africa: literature survey, Internet access and review. Trans R Soc Trop Med Hyg 2000, 94:113-127.

5. Amek N, Bayoh N, Hamel M, Lindblade KA, Gimnig J, Odhiambo F, Laserson KF, Slutsker L, Smith T, Vounatsou P: Spatial and temporal dynamics of malaria transmission in rural Western Kenya. Parasit Vectors 2012, 5:86.

6. Mbogo CM, Mwangangi JM, Nzovu J, Gu W, Yan G, Gunter JT, Swalm C, Keating J, Regens JL, Shililu JI, Githure JI, Beier JC: Spatial and temporal heterogeneity of Anopheles mosquitoes and Plasmodium falciparum transmission along the Kenyan coast. AmJTrop Med Hyg 2003, 68:734-742.

7. Smith T, Charlwood JD, Takken W, Tanner M, Spiegelhalter DJ: Mapping the densities of malaria vectors within a single village. Acta Trop 1995, 59:1-18.

8. Ye Y, Kyobutungi C, Louis VR, Sauerborn R: Micro-epidemiology of Plasmodium falciparum malaria: Is there any difference in transmission risk between neighbouring villages? Malaria J 2007, 6:46.

9. Oesterholt MJ, Bousema JT, Mwerinde OK, Harris C, Lushino P, Masokoto A, Mwerinde $\mathrm{H}$, Mosha FW, Drakeley CJ: Spatial and temporal variation in malaria transmission in a low endemicity area in northern Tanzania. Malaria J 2006, 5:98.

10. Bousema T, Griffin JT, Sauerwein RW, Smith DL, Churcher TS, Takken W, Ghani A, Drakeley C, Gosling R: Hitting hotspots: spatial targeting of malaria for control and elimination. PLoS Med 2012, 9:e1001165.

11. Moonen B, Cohen JM, Snow RW, Slutsker L, Drakeley C, Smith DL, Abeyasinghe RR, Rodriguez MH, Maharaj R, Tanner M, Targett G: Operational strategies to achieve and maintain malaria elimination. Lancet 2010, 376:1592-1603.

12. Dia I, Konate L, Samb B, Sarr JB, Diop A, Rogerie F, Faye M, Riveau G, Remoue F, Diallo M, Fontenille D: Bionomics of malaria vectors and relationship with malaria transmission and epidemiology in three physiographic zones in the Senegal River Basin. Acta Trop 2008, 105:145-153. 
13. Sarr JB, Remoue F, Samb B, Dia I, Guindo S, Sow C, Maiga S, Tine S, Thiam C, Schacht AM, Simondon F, Konate L, Riveau G: Evaluation of antibody response to Plasmodium falciparum in children according to exposure of Anopheles gambiae s.l or Anopheles funestus vectors. Malaria J 2007, 6:117.

14. Nascimento RJ, Santana JM, Lozzi SP, Araujo CN, Teixeira AR: Human IgG1 and IgG4: the main antibodies against Triatoma infestans (Hemiptera: Reduviidae) salivary gland proteins. AmJTrop Med Hyg 2001, 65:219-226.

15. Schwarz A, Sternberg JM, Johnston V, Medrano-Mercado N, Anderson JM, Hume JC, Valenzuela JG, Schaub GA, Billingsley PF: Antibody responses of domestic animals to salivary antigens of Triatoma infestans as biomarkers for low-level infestation of triatomines. Int J Parasitol 2009, 39:1021-1029

16. Caljon G, Van Den Abbeele J, Sternberg JM, Coosemans M, De Baetselier P, Magez S: Tsetse fly saliva biases the immune response to Th2 and induces anti-vector antibodies that are a useful tool for exposure assessment. Int J Parasitol 2006, 36:1025-1035.

17. Poinsignon A, Remoue F, Rossignol M, Cornelie $S$, Courtin D, Grebaut $P$, Garcia A, Simondon F: Human IgG antibody response to Glossina saliva: an epidemiologic marker of exposure to Glossina bites. AmJTrop Med Hyg 2008, 78:750-753.

18. Barral A, Honda E, Caldas A, Costa J, Vinhas V, Rowton ED, Valenzuela JG, Charlab R, Barral-Netto M, Ribeiro JM: Human immune response to sand fly salivary gland antigens: a useful epidemiological marker? AmJTrop Med Hyg 2000, 62:740-745.

19. Marzouki S, Ben Ahmed M, Boussoffara T, Abdeladhim M, Ben Aleya-Bouafif N, Namane A, Hamida NB, Ben Salah A, Louzir H: Characterization of the antibody response to the saliva of Phlebotomus papatasi in people living in endemic areas of cutaneous leishmaniasis. AmJTrop Med Hyg 2011, 84:653-661.

20. Rohousova I, Ozensoy S, Ozbel Y, Volf P: Detection of species-specific antibody response of humans and mice bitten by sand flies. Parasitology 2005, 130:493-499.

21. Doucoure $S$, Mouchet $F$, Cornelie $S$, Deheca JS, Rutee AH, Roca $Y$, Walter A, Herve JP, Misse D, Favier F, Gasque P, Remoue F: Evaluation of the human IgG antibody response to aedes albopictus saliva as a New specific biomarker of exposure to vector bites. PLoS Negl Trop Dis 2012, 6:e1487.

22. Peng Z, Li H, Simons FE: Immunoblot analysis of IgE and IgG binding antigens in extracts of mosquitos Aedes vexans, Culex tarsalis and Culiseta inornata. Int Arch Allergy Immunol 1996, 110:46-51.

23. Estevez PT, Satoguina J, Nwakanma DC, West S, Conway DJ, Drakeley CJ: Human saliva as a source of anti-malarial antibodies to examine population exposure to Plasmodium falciparum. Malaria J 2011, 10:104

24. Londono-Renteria BL, Eisele TP, Keating J, James MA, Wesson DM: Antibody response against Anopheles albimanus (Diptera: Culicidae) salivary protein as a measure of mosquito bite exposure in Haiti. J Med Entomol 2010, 47:1156-1163.

25. Remoue F, Cisse B, Ba F, Sokhna C, Herve JP, Boulanger D, Simondon F: Evaluation of the antibody response to Anopheles salivary antigens as a potential marker of risk of malaria. Trans R Soc Trop Med Hyg 2006, 100:363-370.

26. Balenghien T, Fouque F, Sabatier P, Bicout DJ: Horse-, bird-, and humanseeking behavior and seasonal abundance of mosquitoes in a West Nile virus focus of southern France. J Med Entomol 2006, 43:936-946.

27. Toprak S, Ozer N: Distribution of sand fly (Diptera: Psychodidae) species and efficiency of capturing methods in Sanliurfa province, Turkey. J Med Entomol 2007, 44:23-28.

28. Rizzo C, Ronca R, Fiorentino G, Mangano VD, Sirima SB, Nebie I, Petrarca V, Modiano D, Arca B: Wide cross-reactivity between Anopheles gambiae and Anopheles funestus SG6 salivary proteins supports exploitation of gSG6 as a marker of human exposure to major malaria vectors in tropical Africa. Malaria J 2011, 10:206.

29. Lombardo F, Ronca R, Rizzo C, Mestres-Simon M, Lanfrancotti A, Curra C, Fiorentino G, Bourgouin C, Ribeiro JM, Petrarca V, Ponzi M, Coluzzi M, Arca B: The Anopheles gambiae salivary protein gSG6: an anopheline-specific protein with a blood-feeding role. Insect Biochem Mol Biol 2009, 39:457-466

30. Poinsignon A, Cornelie S, Mestres-Simon M, Lanfrancotti A, Rossignol M, Boulanger D, Cisse B, Sokhna C, Arca B, Simondon F, Remoue F: Novel peptide marker corresponding to salivary protein gSG6 potentially identifies exposure to Anopheles bites. PLoS One 2008, 3:e2472.
31. Rizzo C, Ronca R, Fiorentino G, Verra F, Mangano V, Poinsignon A, Sirima SB, Nebie I, Lombardo F, Remoue F, Coluzzi M, Petrarca V, Modiano D, Arca B: Humoral response to the Anopheles gambiae salivary protein gSG6: a serological indicator of exposure to Afrotropical malaria vectors. PLOS One 2011, 6:e17980.

32. Poinsignon A, Samb B, Doucoure S, Drame PM, Sarr JB, Sow C, Cornelie S, Maiga S, Thiam C, Rogerie F, Guindo S, Hermann E, Simondon F, Dia I, Riveau G, Konate $L$, Remoue F: First attempt to validate the gSG6-P1 salivary peptide as an immuno-epidemiological tool for evaluating human exposure to Anopheles funestus bites. Trop Med Int Health 2010, 15:1198-1203.

33. Poinsignon A, Cornelie S, Ba F, Boulanger D, Sow C, Rossignol M, Sokhna C, Cisse B, Simondon F, Remoue F: Human IgG response to a salivary peptide, gSG6-P1, as a new immuno-epidemiological tool for evaluating low-level exposure to Anopheles bites. Malaria J 2009, 8:198.

34. Gaayeb L, Sarr JB, Ndiath MO, Hanon JB, Debrie AS, Seck M, Schacht AM, Remoue F, Hermann E, Riveau G: Seroprevalence of pertussis in senegal: a prospective study. PLoS One 2012, 7:e48684

35. Ndiath MO, Sarr JB, Gaayeb L, Mazenot C, Sougoufara S, Konate L, Remoue F, Hermann E, Trape JF, Riveau G, Sokhna C: Low and seasonal malaria transmission in the middle Senegal River basin: identification and characteristics of Anopheles vectors. Parasit Vectors 2012, 5:21.

36. Thwing Jl, Perry RT, Townes DA, Diouf MB, Ndiaye S, Thior M: Success of Senegal's first nationwide distribution of long-lasting insecticide-treated nets to children under five - contribution toward universal coverage. Malaria J 2011, 10:86

37. Gillies MT, De Meillon D: The anophelinae of africa south of the sahara (ethiopian zoogeographical region). Johannesburg: South African Institute for Medical Research; 1968.

38. Drame PM, Poinsignon A, Besnard P, Le Mire J, Dos-Santos MA, Sow CS, Cornelie S, Foumane V, Toto JC, Sembene M, Boulanger D, Simondon F, Fortes F, Carnevale P, Remoue F: Human antibody response to Anopheles gambiae saliva: an immuno-epidemiological biomarker to evaluate the efficacy of insecticide-treated nets in malaria vector control. Am JTrop Med Hyg 2010, 83:115-121.

39. Ribeiro JM, Seulu F, Abose T, Kidane G, Teklehaimanot A: Temporal and spatial distribution of anopheline mosquitos in an Ethiopian village: implications for malaria control strategies. Bull World Health Organ 1996, 74:299-305.

40. Schäfer ML: Influence of landscape structure on mosquitoes (Diptera: Culicidae) and dystiscids (Coleoptera: Dystiscidae) at five spatial scales in Swedish wetlands. Wetlands 2006, 26:57-68.

41. Staedke SG, Nottingham EW, Cox J, Kamya MR, Rosenthal PJ, Dorsey G: Short report: proximity to mosquito breeding sites as a risk factor for clinical malaria episodes in an urban cohort of Ugandan children. AmJTrop Med Hyg 2003, 69:244-246.

42. Van Der Hoek W, Konradsen F, Amerasinghe PH, Perera D, Piyaratne MK, Amerasinghe FP: Towards a risk map of malaria for Sri Lanka: the importance of house location relative to vector breeding sites. Int $\mathrm{J}$ Epidemiol 2003, 32:280-285.

43. Drame PM, Machault V, Diallo A, Cornelie S, Poinsignon A, Lalou R, Sembene M, Dos Santos S, Rogier C, Pages F, Le Hesran JY, Remoue F: IgG responses to the gSG6-P1 salivary peptide for evaluating human exposure to Anopheles bites in urban areas of Dakar region. Senegal. Malaria J 2012, 11:72

44. Port GR, Boreham PFL, Bryan JH: The relationship of host size to feeding by mosquitoes of the Anopheles gambiae Giles complex (Diptera: Culicidae). Bull Entomol Res 1980, 70:133-144.

45. Smith T, Killeen G, Lengeler C, Tanner M: Relationships between the outcome of Plasmodium falciparum infection and the intensity of transmission in Africa. AmJTrop Med Hyg 2004, 71:80-86.

46. Fontaine A, Pascual A, Orlandi-Pradines E, Diouf I, Remoue F, Pages F, Fusai $T$, Rogier $C$, Almeras $L$ : Relationship between exposure to vector bites and antibody responses to mosquito salivary gland extracts. PLoS One 2011, 6:e29107.

47. Drame PM, Poinsignon A, Besnard P, Cornelie S, Le Mire J, Toto JC, Foumane V, Dos-Santos MA, Sembene M, Fortes F, Simondon F, Carnevale P, Remoue F: Human antibody responses to the Anopheles salivary gSG6P1 peptide: a novel tool for evaluating the efficacy of ITNs in malaria vector control. PLoS One 2010, 5:e15596.

48. Orlandi-Pradines E, Almeras L, Denis de Senneville L, Barbe $S$, Remoue F, Villard C, Cornelie S, Penhoat K, Pascual A, Bourgouin C, Fontenille D, 
Bonnet J, Corre-Catelin N, Reiter P, Pages F, Laffite D, Boulanger D,

Simondon F, Pradines B, Fusai T, Rogier C: Antibody response against saliva antigens of Anopheles gambiae and Aedes aegypti in travellers in tropical Africa. Microbes Infect 2007, 9:1454-1462.

49. Billingsley PF, Baird J, Mitchell JA, Drakeley C: Immune interactions between mosquitoes and their hosts. Parasite Immunol 2006, 28:143-153.

50. Kalluri S, Gilruth P, Rogers D, Szczur M: Surveillance of arthropod vectorborne infectious diseases using remote sensing techniques: a review. PLoS Pathog 2007, 3:1361-1371.

51. Robert V, Boudin C: Biology of man-mosquito Plasmodium transmission. Bull Soc Pathol Exot 2003, 96:6-20.

doi:10.1186/1756-3305-6-68

Cite this article as: Sagna et al: gSG6-P1 salivary biomarker

discriminates micro-geographical heterogeneity of human

exposure to Anopheles bites in low and seasonal malaria areas. Parasites \& Vectors 2013 6:68

\section{Submit your next manuscript to BioMed Central and take full advantage of:}

- Convenient online submission

- Thorough peer review

- No space constraints or color figure charges

- Immediate publication on acceptance

- Inclusion in PubMed, CAS, Scopus and Google Scholar

- Research which is freely available for redistribution 